\title{
TRAINING A YOUNG CHIMPANZEE TO ATTEND TO ACOUSTIC STIMULI
}

\author{
BY \\ J. A. BIERENS DE HAAN \\ Laboratory of An:mal Psychology of the Royal Zoo'ogical Society \\ "Natura Artis Magistra" at Amsterdam
}

For certain reașons I wished to train a young chimpanzee to choose from two similar boxes the one characterised by the ticking of a metronome inside it.

My subject was a young male chimpanzee (Pan leucoprymnus Lesson), approximately three years old, Tommy by name. He was a good-natured chap, quite tame, and already for some years in captivity. When we knew each other a little better, he would welcome me every morning with a hearty "uhuh", as soon as he heard my steps, and after the experiments of the day we would take leave by shaking hands as old friends. Tommy was rather lazy and not so playful as most young chimpanzees, but this quality made working with him easier and more regular. With a few exceptions it did not give much trouble to make $50-60$ trials with him each day.

The set-up of the experiments was as follows. Two wooden slides were placed against the bars outside his cage, $110 \mathrm{~cm}$ long and $22 \mathrm{~cm}$ wide. At either edge of these slides a wooden rail was fixed, $2 \mathrm{~cm}$ wide, so that a space of $18 \mathrm{~cm}$ was left free between them. In this space a small board could slide, on which a box was fastened, with a base of $20 \times 24 \mathrm{~cm}$ and $30 \mathrm{~cm}$ high. This box was divided into two parts, a lower one, $25 \mathrm{~cm}$ high, in which a metronome was built in, and a upper one, $5 \mathrm{~cm}$ high, which could be opened by lifting a lid, which projected one $\mathrm{cm}$ from the box. In this upper part some food was to be put, which the animal could take out by lifting the lid; the metronome in the lower part of the box could either be set ticking or left silent. Fig. I and 2 will make this clear. On the board below the boxes a rope was fastened, the free end of which could be laid in the cage, so that the animal could easily pull the box towands him. Except when expressely stated to the contrary the boxes were always placed at the end of the slide, about $90 \mathrm{~cm}$ from the bars of the cage.

Now my idea was to set the metronome in one of the boxes ticking, and to 
put a piece of fruit in the upper part of this box, and so to train the animal to pull in the box with the ticking metronome towards him so as to get at the fruit. As a reward for a right choice a piece of apple was chosen of which the animal was very fond. Tommy, for that matter, was something of a connoisseur, and refused to eat carrots or even tomatoes.

When I wound the clockwork of the metronome for the first time and let it tick behind an iron wall of his cage, Tommy was rather disturbed by this

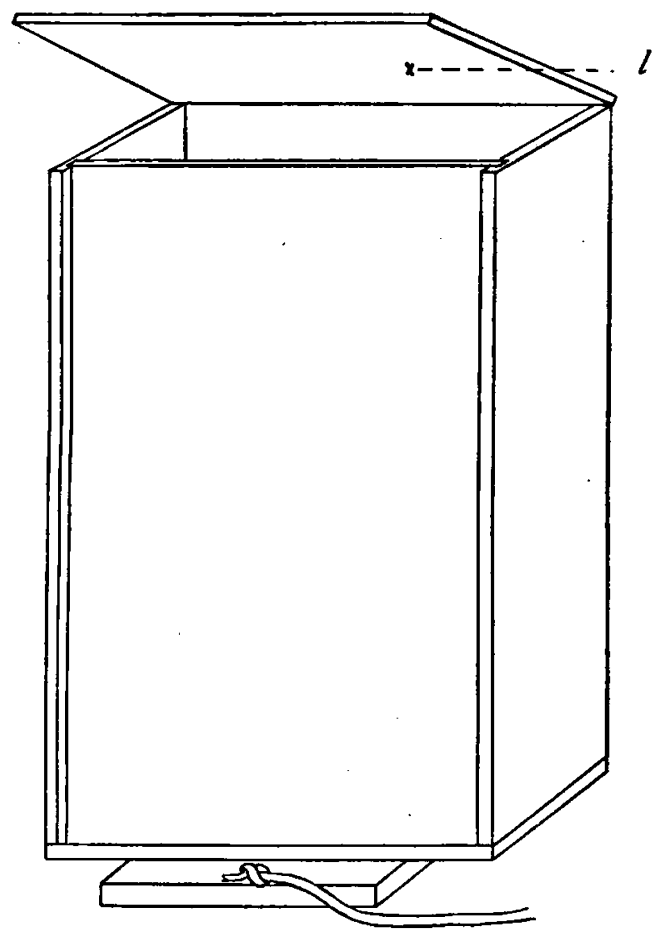

Fig. I. One of the boxes with the lid $(l)$ partly opened

unknown noise and tried to discover what was happening. In general he was very sensitive to noises and often heard unusual noises before I did. Once when a tree was being cut down in the garden near the laboratory in such a way that he heard the noise but could not see what was happening he was so upset and fidgety that it was impossible to work with him that day. Because of this attention to all kinds of noises I thought that it would be rather easy for him to associate the noise of the ticking metronome with the place of the fruit, and that, in a few experiments, he would learn to pull in the box with the ticking metronome. The reverse, however, proved to be the case.

It was no great trouble to train him to pull in the box, open the lid, and to take the fruit, when I put a piece of apple in the box before his eyes. 
I then set the metronome ticking, which again drew his attention, and to which he listened sharply. I could now start my experiments.

To this end a piece of apple was put in one of the boxes, behind the iron wall of his cage and thus invisible to the animal. Then the metronome of that box was set ticking at high speed (about 190 ticks a minute). I then placed both boxes on the slides. In order to prevent him from being trained to pull in either the right- or lefthand box, the place of the box with the

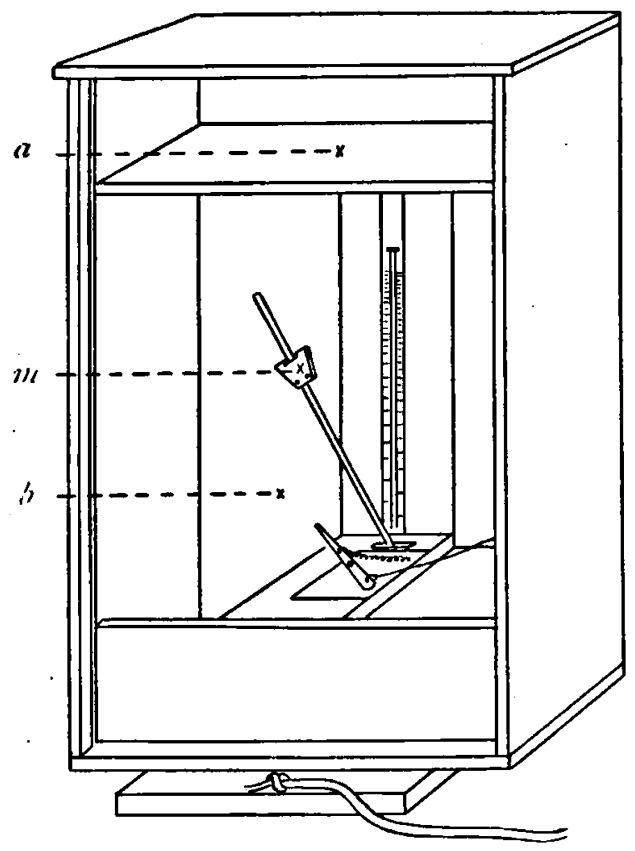

Fig. 2. Box with the front wall removed, so that the pendulum of the metronome $(m)$ is visible. $a$ : upper part of the box where the fruit is laid; $b$ : lower part with metronome

ticking metronome and the food was changed in the following order: L-LR-L-R-L-R-R-L-R ( $R$ and $L$ as seen from the side of the experimenter), a sequence too complicated for the animal to grasp, and in which, in a series of ro trials, the box with the ticking metronome was placed as often on the $\mathrm{L}$-as on the R-side. In order not to influence his choice by the sequence in which the boxes were put on the slides the L-box was as a rule placed first. It was not difficult to train him not to pull in a second box after first pulling the right (or the wrong) box in : except in some experiments in the first days I pulled the cord of the other box away as soon as he had made his choice. For that matter, after a few days' working he soon learned not to try to pull in the other box any more. 
The course of training to choose the box with the ticking metronome was the following.

On the first day after the preliminary experiments I made 4 series of ro trials with the animal. In the first three series he always chose the L-box; in the fourth, a few times, the R-box. The result of that day was $53 \%$ right and $47 \%$ wrong choices.

This position-habit (the choosing not by some special characteristic of the boxes but by their place in the set-up) was persisted in during the second and third days. He then always chose the L-box; so his score was $50 \%$ right choices on both days. As on the fourth day he started with L-choices again, I inserted, after the third series, one of forced R-choices by placing the cord of the L-box so far away that he could not reach it from his place inside the cage. I hoped in this way to break his position-habit, but in vain: when after this extra-series I gave him two more series in the normal way he again persisted in choosing the L-box.

On the fifth day I made a more serious attempt to break his L-choice habit. I first made a series in which the cord of the L-box was beyond his reach, so that he was forced to choose the $R$ one, where he then found the fruit. Then, in a second series, the fruit was always put in the R-box, while he was given a chance to correct his choice if he had chosen the $\mathrm{L}$ one. In a third series, in half of the trials, the fruit was put in the R-box before his eyes. In the fourth and fifth series too the fruit was always put in the R-box. The result was that only if $I$ put the fruit in the R-box before his eyes, this one was pulled in: in other cases the L-box was invariably chosen.

When I continued like this on the sixth day, the result was that now he transferred his preference to the R-box. When after two series, in which the fruit was always in the R-box, I again followed the original sequence, he nearly always chose the R-box, so that his score in the last 30 trials was $47 \%$ right and $53 \%$ wrong choices. The seventh day too he made practically speaking only R-choices.

It was clear that I had to help him in another way to overcome this positionhabit. In order to draw his attention more to the box with the ticking metronome, I fastened to this box a piece of white cardboard, $5 \times 5 \mathrm{~cm}$, on which a red circle of $3 \mathrm{~cm}$ diameter had been stuck. For an animal with colour-sense like the chimpanzee this mark was very conspicuous and could not fail to strike him. By the eighth day, however, this help had not yet had any effect. Invariably his choice was $R$. On the ninth day I added a new mark to the right box: I placed it half-way in the slide, about $45 \mathrm{~cm}$ before the other one, so that it became still more conspicuous. Yet he always chose the R-box. But on the tenth day, in the first two series he chose right 8 and ro times, and when then I put the right box (with the red circle and ticking metronome) at the same distance as the other one he chose, in three series, respectively 7,7 , and 5 times the right box. And on the I Ith day he chose the right box (with 
ticking metronome and the red circle) if this was placed at half-distance, but also if it stood only $20 \mathrm{~cm}$ or even $10 \mathrm{~cm}$ before the other one. In a control series with equal distances for both boxes he again, however, chose invariably the R-box.

It was clear, therefore, that it was very easy for him to learn to choose a box, if this showed the visual characteristic of standing some distance before the other one. This was proved again the next (I2th) day, when he chose rightly whenever the box was placed at $10 \mathrm{~cm}$, or $5 \mathrm{~cm}$, or even $2 \frac{\mathrm{T}}{2} \mathrm{~cm}$ before the other one. And when I then placed both boxes at equal distances, he chose, in two series, 7 and 8 times the right box.

He now seemed to have been trained to choose the box which was characterised by three marks: 1 . the ticking of the metronome, 2. the red circle, and 3. its place some $\mathrm{cm}$ before the other one. On the $13^{\text {th }}$ day I tried to analyse this complex. Would he be able to choose the right box also when one or two marks of this complex were left out? The result is shown in the following table:

Series I. Food-box with ticking metronome and red circle, placed $2 \frac{1}{2} \mathrm{~cm}$ before the other one. Result: Io right choices.

Series II. Food-box with red circle and placed $21 / 2 \mathrm{~cm}$ before the other one, but with silent metronome: Io right choices.

Series III. Food-box with red circle and ticking metronome, but at equal distance with the other one: Io right choices.

Series IV. Food-box with ticking metronome and $2 \frac{\mathrm{T}}{2} \mathrm{~cm}$ before the other one, but without red circle: Io right choices.

Series V. Food-box only with red circle: Io right choices.

Series VI. Food-box only $21 / 2 \mathrm{~cm}$ before the other one: ro right choices.

Series VII. Food-box only characterised by thicking metronome: Io right choices.

My conclusion - rightly as I thought - was now : the animal after having learned to choose the box with a ticking metronome, a red circle, and placed somewhat before the other one, succeeded in separating these three elements in the complex, and had now learned, via a detour, to do what I tried to get him to do, viz. to choose the box which was characterised by the ticking of a metronome. This conclusion seemed justified. Yet it was premature!

Till then I had for convenience's sake always used the same box for the "positive" one. Calling the boxes A and B, I had always used box A and its ticking metronome as the positive one, as I thought both boxes exactly similar. The desillusion came on the 14th day: when then I used again box A as the positive one with only the metronome ticking, the animal chose $100 \%$ right, but when, as a control, I used box $B$ with the ticking metronome, he chose this box only 4 and $\mathrm{I} X$ in two series of 10 trials, thereby demonstrating clearly that he was not at all trained to choose the box with the ticking metronome, but only to choose box A! 
I must confess that I felt somewhat baffled by this failure, the more so as I might have foreseen it. In former (un-published) experiments with a young orang $I$ once tried to train the animal to distinguish between two similar boxes, with a base of $18 \times 22 \mathrm{~cm}$ and $8 \mathrm{~cm}$ high in the front and $18 \mathrm{~cm}$ at the back, so that the lid of the boxes hung down obliquely. On each of these lids a white piece of cardboard, great $20 \times 20 \mathrm{~cm}$, was fixed, on one of which a red triangle with sides of $10 \mathrm{~cm}$ was stuck, while on the other one a blue circle was stuck with a diameter of $8 \mathrm{~cm}$. While I trained the animal to choose the red triangle I made the same mistake as I did this time with Tommy, viz. for convenience's sake I did not, at first, change the cardboard on the boxes, but always used the same box as the positive one. When, after the training seemed to be completed, in a control experiment I changed the cards on the boxes, it turned out that, here too, the animal had not been trained to choose the box with the red triangle, but the special box which I had used until then as the positive one. I wondered how the animal managed to do that, as to me the boxes were exactly alike, and I could not find at first any difference between them; at any rate not one so conspicuous as the coloured figures on it. On closer examination, however, I did find a difference: on the box used until then as the positive one the lid was about $I \mathrm{~cm}$ longer than on the other, with the result that the animal could not see the two upper ones of four small nails, driven into the four front corners. The animal, therefore, was not trained to choose the box with the red triangle, but the one where only two instead of four nails were visible! After I had planed off the lid a little so that on the positive box, too, four nails were visible, the animal was at first quite confused. It took me about 350 experiments to train him to choose the box with the red triangle. This shows how utterly different an animal's perception of an object may be from that of man. For us, the boxes were no more than a background for the red triangle and the blue circle, which were visible and distinguishable from a great distance; for the animal, although he possessed a colour sense like ours, these coloured figures did not count, but he distinguished the boxes by the number of nails he could see in the front wall!

But to return to Tommy : by the end of the 14th day we had got so far that it was clear that the animal had not trained himself to choose the box with the ticking metronome, but simply to choose box A. What was, for him, the difference between the boxes I was not able to discover. No two wooden boxes are, of course, ever absolutely alike; so in this case it seemed to me that the triplex wood of which box A was made was somewhat lighter in colour than that of box B. But below we will see that even when the front walls of the boxes were taken away the saw a difference between the two. However, my task was now to break this habit of always choosing box A.

I therefore made box $B$ positive by letting its metronome tick, putting the fruit in its upper part, and placing the box $2 \frac{1}{2} \mathrm{~cm}$ before the other one. The result was now that in two series of ro trials he chose 5 and 7 times right. 
This proved that, all the same, he was not simply trained to choose box A (otherwise he would have made Io errors in each series now) but that he hesitated between box $\mathrm{A}$ and the box that stood a little before the other.

The following days I tried to train him in this way to choose box B, or, rather, to break his habit of always choosing box $\mathrm{A}$. To this end box $\mathrm{B}$ was made positive with ticking metronome and put $21 / 2 \mathrm{~cm}$ before box $A$. The results were:

\begin{tabular}{|c|c|c|c|c|}
\hline I 6 th & $\|: 6,7,6,7$ & $"$ & " & $(65 \%)$ \\
\hline $7 t$ & $": 8,6,9,6,6$ & " & $"$ & $(70 \%)$ \\
\hline $8 t$ & $": 8,9,8$, 10 & " & " & $(87 \%)$ \\
\hline & $": 7,9,6,5,8$ & $"$ & $"$ & $(70 \%)$ \\
\hline &,$: 7,9,7$ & $"$ & ", & $(77 \%)$ \\
\hline
\end{tabular}

The succes was not overwhelming, and the number of right choices did not rise. On that last day a visitor suggested that perhaps the two boxes were standing too close together, so that it was not possible for the animal clearly to localize the place of the ticking metronome. Although it seemed to me improbable that this would be the cause of the failure I placed the slides with the boxes $75 \mathrm{~cm}$ apart. This change at first completely confused him. When on the 2 iste day, I put the two boxes at equal distances on the slides and made box $\mathrm{B}$ the positive one, he backslided to a simple $\mathrm{R}$-choice, even when, in the last series, I put the fruit on the lid of the box so that he could easily see it.

Fortunately, he had overcome his confusion the next day. Whether it helped him that, on that day and the following ones, I put the boxes only $50 \mathrm{~cm}$ apart, I cannot say. When I put the fruit on the lid of box $B$ he pulled it in, whether the metronome was ticking or not. From time to time he lifted the lid as if to see whether there might not be some fruit inside as well. If box A was then made positive with ticking metronome and placed $5 \mathrm{~cm}$ to the fore he chose it Io times in a series of Io trials; box $\mathrm{B}$ under similar conditions was chosen 7,9 , and 7 times out of Io. The next day the numbers were Io times right choice for box $\mathrm{A}$, and 9 and 8 for box B. But when the boxes were then put at equal distances, he made 9 right choices with box $A$ as the positive box, but only 6 with box B. It was now clear that with the boxes at equal distances box $\mathrm{A}$ with ticking metronome still attracted him more than box $B$ under the same conditions. But it was also clear that the ticking too influenced his choice. Otherwise, he would always have choosen $A$, whenever there was a choice between $A$ without ticking and B with ticking, as he did when he heard the ticking in box A. He was on the right road, therefore; all that was necessary now was to distract him from $10 \mathrm{oking}$, and get him to listen.

As it had become clear from the former experiments that his failure to 
learn was due to the fact that his attention was drawn to the $\mathrm{v}$ is $\mathrm{u}$ a $\mathbf{l}$ and not to the acoustical, marks of the situation, which I wished to train him to attend to, I asked myself if it was not possible to come to a result by making a closer connection between the accoustical characteristic I had chosen as the distinguished mark, viz. the sound of the metronome, and some visual mark that would be sure to draw his attention. What would happen if I removed the frontwall of the boxes, so that he could at the same time se e the motion of the pendulum of the metronome and $h$ e a $r$ the ticking sound? Should not this combination draw his attention to the ticking?

When I did this on the 27th day (see Fig. 2; the upper part of the box, with the fruit, was then closed by a piece of cardboard) he chose box A (made positive) 8 times in ro trials and box B 4 times in Io trials. The 28th day he chose box A 9 times and box B 7 times in Io trials. This proved that his old preference for box A was not yet quite lost, and that he saw a difference between the boxes as such even when the front walls were taken away. I then decided to train him first to choose box $B$ with visib!e meironome, in the hope that, if that succeeded, he would transfer this choosing of the ticking metronome from box $B$ to box $A$. The results of this training were:

$$
\begin{aligned}
& \text { 29th day: } 6,7,4,7,5 \text { right choices }(58 \%) \\
& \text { 30th } ": 7,7,8,7,8 \text { right choices }(74 \%) \\
& 3^{\text {Ist }} ": \text { (this day, for some reason, he would not work well) } \\
& 3^{2 \mathrm{~d} .},: 8,7,9,9, \text { Io right choices }(86 \%)
\end{aligned}
$$

This last day, for the first time, he showed a real choosing: he hesitated between both boxes before making his choice, and sometimes even changed his first choice to another one, dropping the rope before he had entirely pulled in a box in order to pull in the other one. So he chose f.i. first A, then $B$, then again definitely $A$ (wrong choice) or even first $A$, then $B$, then again $A$, then again $B$ (right choice). As in the last series of the day he made no errors $I$ felt that he was at last on the right road. The 33 d day he chose faultlessly in 20 trials with box $B$ as the positive one; when $I$ then made box $A$ positive he chose 3 and 7 and 6 times right. There was now a preference for the B-box, but I felt this would soon diminish. The $34^{\text {th }}$ day when box $B$ was positive he chose it 9 and ro times; when $A$ was positive 9 and 9 times in a series of ro trials. He now clearly made the impression of attending to the moving pendulum. On the $35^{\text {th }}$ day he made two series, one with box $\mathrm{A}$ as the positive one, and one with box $\mathrm{B}$ as the positive one, both with faultless choices.

A tense moment had now come for me. Was he now trained to choose the box where he $\mathrm{saw}$ the moving of the pendulum of the metronome, or the box where he hea rd it ticking? Or, if he was trained to chose on both stimuli, would he be able to separate them and determine his choice by the acoustic one alone? Only one experiment could decide this : closing the boxes 
by putting the front walls back in their places. When I did this and made box $A$ the positive box (with as only characteristic the ticking metronome inside) he chose it 9 times out of Io trials; when I made box B positive in the same way he chose it Io times in Io trials. So finally, after more than I 500 trials I got what I had wanted from the start: after a long detour I had trained Tommy to choose from two similar boxes the one where he heard a metronome ticking inside. Further experiments, to which those reported here were only introductory, subsequently proved the truth of this conclusion. 